\title{
Upper gastrointestinal endoscopy in children: The Lagos University Teaching Hospital experience
}

\author{
O F Adeniyi, ${ }^{1}$ MBBS, FMC (Paed), MSc (Child Health); O A Lesi, ${ }^{2}$ MBBS, FWACP; E A Odeghe,${ }^{2}$ MBBS, FWACP; \\ O Adekola, ${ }^{3} \mathrm{MBBS}, \mathrm{FMC}$ (Anaesth); O A Oduwole, ${ }^{4} \mathrm{MBBS}, \mathrm{FWACP}$ \\ ${ }^{1}$ Department of Paediatrics, College of Medicine, University of Lagos/Lagos University Teaching Hospital, Nigeria \\ ${ }^{2}$ Department of Medicine, College of Medicine, University of Lagos/Lagos University Teaching Hospital, Nigeria \\ ${ }^{3}$ Department of Anaesthesia, College of Medicine, University of Lagos/Lagos University Teaching Hospital, Nigeria \\ ${ }^{4}$ Department of Paediatrics, College of Medicine, University of Lagos/Lagos University Teaching Hospital, Nigeria
}

Corresponding author: OF Adeniyi (layo_funke@yahoo.co.uk)

\begin{abstract}
Background. Paediatric endoscopy is now standard care in the developed world for the management of gastrointestinal (GI) disorders However, in developing countries endoscopy remains an underutilised tool.

Objective. To determine the indications and the spectrum of endoscopic findings in children seen at the Lagos University Teaching Hospital, Nigeria.

Methods. The indications for upper GI endoscopy and endoscopic findings in children $\leq 16$ years old, referred for the procedure from June 2013 to June 2016, were documented. The endoscopic yield in these children was also determined.

Results. In total 71 children were referred for upper GI endoscopy during the study period. There were 35 boys and 36 girls aged 3 months to 16 years. The indications for upper endoscopy were recurrent abdominal pain in 37 (52.1\%), upper GI bleeding in 17 (23.9\%), recurrent vomiting in $7(9.9 \%)$, dyspepsia in $5(7.0)$, heartburn in $2(2.8 \%)$, dysphagia in $1(1.4)$, portal hypertension in $1(1.4)$ and ingestion of corrosives in $1(1.4 \%)$ of the subjects. Endoscopic findings were as follows: gastritis 19 (26.8\%), hiatus hernia in 13 (18.3\%), gastric erosions in $12(16.9 \%)$, oesophageal varices $6(8.4 \%)$, duodenitis in $4(5.6 \%)$, gastric ulcer in $3(4.2 \%)$, gastric polyp in $2(2.8 \%)$. The overall endoscopic yield was $60.2 \%$.

Conclusion. There is a need to increase the awareness of the role of paediatric endoscopy in the diagnosis and treatment of GI disorders in developing countries. Recurrent abdominal pain still remains a relevant indication for the procedure. The need to develop training programmes for paediatric endoscopy and paediatric gastroenterology in general in developing countries cannot be overemphasised.
\end{abstract}

S Afr J Child Health 2016;10(4):207-210. DOI:10.7196/SAJCH.2016.v10i4.1116

With the introduction of flexible upper gastrointestinal (GI) endoscopic procedures in the 1970s and development of more instruments in the 1990s, paediatric endoscopic procedures have now become standard care in the developed world for the management of GI disorders. ${ }^{[1]}$ In developing countries upper GI endoscopy remains an underutilised tool in the care and management of these paediatric disorders. This is more so in sub-Saharan countries, where accessibility and affordability are still very limited.

Previous studies documenting the indications and endoscopic findings in children have been mainly from developed countries, ${ }^{[2-5]}$ and few reports are available from developing countries, especially from sub-Saharan Africa. In Sudan, the most common indication for upper GI endoscopy was haematemesis (24\%) and portal hypertension (PHT) (21\%), while the most common endoscopic findings were oesophageal varices $(16 \%)$ and gastritis $(7 \%) .{ }^{[6]}$ In Uganda, gastritis and duodenal ulcers were found to be the most common endoscopic findings. ${ }^{[7]}$

There is a dearth of information on the utility of the procedure in children, especially in the West African sub-region. Therefore, this study was carried out to outline the indications and the spectrum of endoscopic diagnosis in children seen at the Lagos University Teaching Hospital (LUTH)

\section{Methods}

We conducted a prospective, descriptive study at the endoscopy centre of LUTH in Nigeria, from June 2013 to June 2016. All consecutive children referred to the endoscopy unit for the procedure were enrolled into the study. LUTH is a tertiary referral hospital in Lagos, Nigeria, and its endoscopy centre, which offers both training and service facilities, is one of the centres in the Nigeria providing both diagnostic and therapeutic upper GI endoscopy services to both adult and paediatric populations from all over the country.

All children $\leq 16$ years old referred for upper endoscopy, both from the outpatient clinics and inpatient wards during the study period, were enrolled into the study. Children who were referred for endoscopy included those with recurrent abdominal pain (usually children who had experienced abdominal pain for $\geq 3$ months) and patients with abdominal pain for whom the attending physician requested the procedure. Subjects with other appropriate symptoms, namely upper GI bleeding, recurrent and intractable vomiting, ingestion of corrosives, unexplained anorexia, unexplained weight loss or failure to thrive, unexplained anaemia and evidence of PHT, were also referred for the procedure.

\section{Definition of terms}

- Dyspepsia: Presence of troublesome pain or discomfort located in the upper part of the abdomen (epigastrium) and/or nausea, early satiety or uncomfortable feeling of fullness after meals. ${ }^{[8,9]}$

- Epigastric pain: Troublesome pain or discomfort located in the epigastric region of the abdomen. ${ }^{[8,9]}$

- Abdominal pain: Troublesome pain or discomfort indicated anywhere in the abdomen. ${ }^{[8,9]}$

- Heartburn: Burning pain in the chest and possibly retrosternal pain, which is often worse when lying down or bending over. ${ }^{[8,9]}$

These symptom definitions were adapted from the validated Abdominal Symptom Questionnaire (ASQ) ${ }^{[8,9]}$ which describes the abdominal symptoms from the upper and lower part of the abdomen. 
The ASQ is a validated document describing the presence or absence (yes/no) of 27 troublesome GI symptoms over the preceding 3 months, and also includes the abdominal pain location. This document has been validated to ascertain pain and found to have a high sensitivity and specificity. The document was adapted for this study in order to describe the GI symptoms in the subjects accurately.

The basic demographic data and indications for the procedure and endoscopic findings were entered into a standardised proforma.

The basic work-up for each subject referred on account of abdominal pain included stool examination done for ova, parasites, occult blood and faecal antigen for Helicobacter pylori. An abdominal scan was also carried out. Other investigations carried out for each patient were based on the clinical suspicion of the underlying condition.

Prior to the procedure, each child was requested to undergo an overnight fast - the procedure was performed the next morning. The Karlz Storz video endoscope (model 13821 PKS/NKS, Germany) was used to perform the procedures, and endoscopic diagnosis was based on visual evaluation in collaboration with experienced endoscopists. Each procedure was carried out after a venous access was established for the child and the vital signs and oxygen saturation were monitored. Two endoscopy nurses assisted with the procedure.

\section{Sedation}

For children $>5$ years old sedation was performed using $1 \%$ local lignocaine spray to anaesthetise the oropharynx. Subsequently, each child was given intravenous (IV) midazolam at $0.5 \mathrm{mg} / \mathrm{kg}$, IV pentazocine at $0.5 \mathrm{mg} / \mathrm{kg}$ and IV Buscopan $0.5 \mathrm{mg} / \mathrm{kg}$ for conscious sedation. For children $<5$ years similar drugs were administered and intravenous ketamine $1 \mathrm{mg} / \mathrm{kg}$ was added to achieve adequate sedation.

IV ketamine was added to the above medications in 35 subjects with ages between 3 months and 14 years ( 21 males and 14 females) to achieve adequate sedation for carrying out the procedure successfully.

Sedation was performed with the assistance of the anaesthetists, especially for children $<6$ years old. None of the patients had general anaesthesia and no adverse reaction to the sedative agents was recorded in the subjects.

\section{Statistical analysis}

Data were entered and analysed using SPSS version 21 (SPSS Statistics for Windows, version 21.0, IBM Corp., USA). Basic

Table 1. Clinical characteristics of the subjects in the study

\begin{tabular}{ll}
\hline Parameter & $\boldsymbol{n}(\%)$ \\
\hline Age $(\mathrm{yr})$ & $71(100)$ \\
$<5$ & $18(25.4)$ \\
$5-9$ & $28(39.4)$ \\
$10-15$ & $21(29.6)$ \\
$>15$ & $4(5.6)$ \\
Sex & \\
Male & $35(49.3)$ \\
Female & $36(50.7)$ \\
Religion & \\
Christian & $54(76.0)$ \\
Muslim & $17(24.0)$ \\
Ethnicity & \\
Yoruba & $46(64.8)$ \\
Igbo & $35(35.2)$
\end{tabular}

descriptive statistics were performed and displayed as frequency tables. Continuous data and categorical data were compared using Student's $t$-test, $\chi^{2}$ test and Fischer's exact test, where appropriate.

\section{Ethical considerations}

The study was approved by the Health Research and Ethical Committee of LUTH. A brief discussion was held with the parents and the child prior to the procedure, during which details of the procedure were explained. Thereafter, written informed consent was obtained from the parents, and consent was also obtained from the child where appropriate, before he or she was enrolled in the study.

\section{Results \\ General characteristics}

A total of 71 children had upper GI endoscopy during the study period. The patients were aged 3 months to 16 years. The mean (standard deviation (SD)) age was 7.8 (3.8) years. There were $35(49.3 \%)$ males and $36(50.7 \%)$ females.

The largest group of subjects was aged 5 - 9 years (28.0\%). Most were Christian (76\%) and belonged to the Yoruba tribe (64.8\%) (Table 1). The means (SDs) for the weights and heights of the subjects were $23.8(12.2) \mathrm{kg}$ and $117(32.6) \mathrm{cm}$, respectively. All the subjects were retroviral-disease-negative. Two of the subjects had haemoglobinopathy (HbSC and HbSS).

\section{Indications for endoscopy}

The most common indication for upper endoscopy was recurrent abdominal pain, present in 37 (52.1\%), followed by upper GI bleeding in $17(23.9 \%)$ and recurrent vomiting in $7(9.9 \%)$. Heartburn in 2 (2.8\%), dysphagia in $1(1.4 \%)$ and ingestion of corrosive substance 1 (1.4\%) were the least common indications for the procedure (Table 2).

Four of the subjects with abdominal pain had dyspepsia and three of these localised the pain as being epigastric. One of the subjects, a patient with known HbSS, was referred for screening endoscopy following an abdominal computed tomography (CT) scan diagnosis of PHT. Six of the subjects who presented with upper GI bleeding had ingested herbal preparations while three of them had been on non-steroidal anti-inflammatory drugs (NSAIDs) prior to presentation.

\section{Endoscopic findings}

The most common endoscopic finding in this study was gastritis, seen in $19(26.8 \%)$ of the subjects. Hiatus hernia was seen in $16(18.3 \%)$. Twelve (16.9\%) had gastric erosions, 11 (15.5\%) had normal studies while $6(8.4 \%)$ had oesophageal varices. Gastric ulcers and gastric polyps were found in $3(4.2 \%)$ and $2(2.8 \%)$ subjects, respectively (Table 3).

Table 2. Indications for endoscopy in children

\begin{tabular}{ll}
\hline Indication & $\boldsymbol{n}(\%)$ \\
\hline Recurrent abdominal pain & $37(52.1)$ \\
Upper GI bleeding & $17(23.9)$ \\
Dyspepsia & $5(7.0)$ \\
Recurrent vomiting & $7(9.9)$ \\
Heartburn & $2(2.8)$ \\
Dysphagia & $1(1.4)$ \\
PHT & $1(1.4)$ \\
Ingestion of corrosive substance & $1(1.4)$ \\
Total & $71(100)$ \\
${ }^{*}$ Three patients with recurrent abdominal pain also had epigastric pain.
\end{tabular}


Table 4 shows the endoscopic findings in relation to the indications in the subjects. The biggest group of subjects with recurrent abdominal pain had gastritis $(33.3 \%)$ while $21.4 \%$ of them had hiatus hernia. Similarly, a significant group of the subjects (35.3\%) with upper GI bleeding had gastric erosions. Oesophageal varices occurred in $23.5 \%$ of the subjects, while $57.1 \%$ of the subjects with recurrent vomiting had hiatus hernia.

The indication for endoscopy was significantly associated with the endoscopic findings $(p=0.000)$ while gender, ethnicity and the nutritional status were not significantly related to the endoscopic findings $(p>0.05)$.

\section{Endoscopic yield}

Table 5 shows the endoscopic yield in relation to the major indications and significantly abnormal endoscopic findings. The overall endoscopic yield obtained in this study was $60.2 \%$. The highest yield was obtained for upper GI bleeding (82.4\%) while the lowest yield was for heartburn/dyspepsia (42.8\%). Just over $40 \%$ of children with recurrent abdominal pain had endoscopic evidence of pathology.

\section{Outcome in subjects post endoscopy}

Twelve $(66.7 \%)$ of the 18 subjects with gastritis were $H$. pyloripositive and had triple therapy with amoxicillin, clarithromycin and omeprazole.

Four of the six subjects with oesophageal varices had underlying chronic liver disease from biliary atresia, hepatitis B infection or idiopathic causes.

All the subjects with varices were on propranolol therapy post endoscopy and two of them have had variceal banding done. However, the HbSS patient died during admission. Six (35\%) and $2(11.8 \%)$ of the subjects with gastric erosions who presented with GI bleeding used herbal preparations and NSAIDs, respectively, prior to presentation. They were counselled against the use of these agents subsequently.

All subjects with gastric erosions/ulcers, duodenitis and hiatus hernia were also treated with proton pump inhibitors.

All the subjects are being followed up in the paediatric outpatient clinic of LUTH.

\section{Discussion}

In this study, the most common indication for endoscopy was recurrent abdominal pain, which was seen in just over half the subjects. This finding is higher than in some reports from other developing countries where recurrent abdominal pain constitutes 8 - $43 \%$ of the endoscopic indications. ${ }^{[6,10-12]}$ Okello et al. ${ }^{[13]}$ in Uganda observed that $67.4 \%$ of the 135 children undergoing the procedure in a tertiary hospital had recurrent abdominal pain. Recurrent abdominal pain is a common presentation in children and is a frequent reason for referral to the paediatric gastroenterologist with a request for upper GI endoscopy. ${ }^{[14-16]}$

Upper GI bleeding was another important indication for endoscopy observed in our study, and was seen in $23.9 \%$ of the subjects. In Sudan, upper GI bleeding, especially secondary to PHT, is the most common reason for paediatric upper GI endoscopy ${ }^{[6]}$ This is believed to be related to the endemicity of schistosomiasis in the country.

Dysphagia and heartburn were the least common reasons for performing endoscopy in the present study; these indications

Table 3. Endoscopic findings in children

\begin{tabular}{ll}
\hline & Endoscopic diagnosis $\boldsymbol{n}$ (\%) \\
\hline Gastritis & $19(26.8)$ \\
Hiatus hernia $^{*}$ & $13(18.3)$ \\
Gastric erosions & $12(16.9)$ \\
Normal & $11(15.5)$ \\
Oesophageal varices ${ }^{\dagger}$ & $6(8.4)$ \\
Duodenitis & $4(5.6)$ \\
Gastric ulcer & $3(4.2)$ \\
Gastric polyp & $2(2.8)$ \\
Achalasia & $1(1.4)$ \\
Total & $71(100)$ \\
${ }^{*}$ Three patients with recurrent abdominal pain had epigastric pain. \\
${ }^{\dagger}$ One subject with oesophageal varices also had gastric varices and evidence of \\
portal hypertensive gastropathy. \\
${ }^{\ddagger}$ One subject with a gastric polyp also had a duodenal polyp.
\end{tabular}

Table 4. Indications for endoscopy and endoscopic findings in the subjects

\begin{tabular}{|c|c|c|c|c|c|c|c|c|c|c|}
\hline \multirow[b]{2}{*}{ Indication } & \multirow[b]{2}{*}{ Total $(n)$} & \multicolumn{9}{|c|}{ Endoscopic finding, $n(\%)$} \\
\hline & & Normal & Gastritis & $\begin{array}{l}\text { Hiatus } \\
\text { hernia }\end{array}$ & $\begin{array}{l}\text { Oesophageal } \\
\text { varices }\end{array}$ & $\begin{array}{l}\text { Gastric } \\
\text { polyp }\end{array}$ & $\begin{array}{l}\text { Gastric } \\
\text { erosions }\end{array}$ & $\begin{array}{l}\text { Gastric } \\
\text { ulcer }\end{array}$ & Duodenitis & Achalasia \\
\hline $\begin{array}{l}\text { Recurrent } \\
\text { abdominal } \\
\text { pain }\end{array}$ & 37 & $6(16.2)$ & $11(29.7)$ & $8(21.6)$ & $1(2.7)$ & $2(5.4)$ & $5(13.5)$ & - & $4(10.8)$ & - \\
\hline $\begin{array}{l}\text { Upper GI } \\
\text { bleeding }\end{array}$ & 17 & $3(17.6)$ & $4(23.5)$ & - & $3(17.6)$ & - & $6(35.3)$ & $1(5.9)$ & - & - \\
\hline $\begin{array}{l}\text { Recurrent } \\
\text { vomiting }\end{array}$ & 7 & $1(14.3)$ & $1(14.3)$ & $4(57.1)$ & - & - & - & $1(14.3)$ & - & - \\
\hline Dyspepsia & 5 & - & $3(60.0)$ & $1(20.0)$ & - & - & - & $1(20.0)$ & - & - \\
\hline Heartburn & 2 & & - & - & $1(50.0)$ & - & $1(50.0)$ & - & - & - \\
\hline Dysphagia & 1 & - & - & - & - & - & - & - & - & $1(100.0)$ \\
\hline PHT & 1 & - & - & - & $1(100.0)$ & - & - & - & - & \\
\hline $\begin{array}{l}\text { Ingestion } \\
\text { of } \\
\text { corrosive } \\
\text { substance }\end{array}$ & 1 & $1(100.0)$ & - & - & - & - & - & - & - & \\
\hline Total & 71 & $11(15.5)$ & $19(26.8)$ & $13(18.3)$ & $6(8.5)$ & $2(2.8)$ & $12(16.9)$ & $3(4.2)$ & $4(5.6)$ & $1(1.4)$ \\
\hline
\end{tabular}


Table 5. Endoscopic yield in children

\begin{tabular}{lll}
\hline Major indications & $\boldsymbol{N}$ & $\begin{array}{l}\text { Children with significant } \\
\text { abnormal endoscopic findings, } \\
\text { endoscopic yield, } \boldsymbol{n}(\%)\end{array}$ \\
\hline Recurrent abdominal pain & 37 & $20(42.9)$ \\
Upper GI bleeding & 17 & $14(82.4)$ \\
Recurrent vomiting & 7 & $4(57.1)$ \\
Heartburn and dyspepsia & 7 & $3(42.8)$ \\
Total & 68 & $41(60.2)$
\end{tabular}

do not appear to be documented in many paediatric endoscopic studies. ${ }^{[2,5-7,10-13]}$

In terms of endoscopic findings, $15.5 \%$ of our subjects had normal studies while the most common finding was gastritis (25.3\%). Studies done in Pakistan, Saudi Arabia and Colombia have also reported similar findings. ${ }^{[6,12,14-16]}$ In the Colombian study, the reason was linked to a high prevalence of $H$. pylori in the subjects, where up to $70 \%$ of the subjects had $H$. pylori colonisation. ${ }^{[14]}$ Other authors have corroborated this finding, ${ }^{[15-17]}$ and in our study two-thirds of the subjects with gastritis were positive for $H$. pylori. The majority of these subjects also presented with abdominal pain. Therefore, it appears that in children with recurrent abdominal pain, there is the need to screen for this organism and to have a high index of suspicion for gastritis when the screening test is positive.

Other significant findings in our study were hiatus hernia, which was seen in $18.3 \%$. One-fifth $(21.3 \%)$ of the subjects with hiatus hernia also presented with abdominal pain. Half of the subjects with gastric erosions had ingested herbal preparations, a common phenomenon in developing countries. Therefore there is a need to evaluate for the use of herbal preparations and even the use of NSAIDs in children who present with upper GI bleeding, especially when there is no evidence of underlying liver disease. In our cohort, very few subjects had duodenal lesions compared with other studies. ${ }^{[18,19]}$ The reason for this finding is not clear.

The overall endoscopic yield obtained in this study was $60.2 \%$, which is higher than reports by El-Mouzan et al. ${ }^{[18]}$ in Saudi Arabia (43\%) and Sheiko ${ }^{[20]}$ in the USA $(34 \%)$. It must be noted that endoscopic yield remains a function of the indication for the procedure and possibly the expertise of the endoscopist. The high yield obtained in this study may be related to the small number of subjects studied. The best diagnostic yield was for upper GI bleeding $(81.8 \%)$ in this study. Other authors have also reported a high diagnostic yield for this symptom. ${ }^{[17-20]}$ Upper GI bleeding has been reported to be an important indication for endoscopy and constitutes one of the alarm symptoms that warrant urgent endoscopy.

Upper GI endoscopy remains a very useful diagnostic and therapeutic tool in the management of GI disorders. The overall symptomatology of the patients and the anticipated endoscopic yield should be taken into consideration before the procedure is performed on any child, however.

\section{Study limitations}

The main limitation of the study was the small number of subjects studied. The histopathological results were not available for inclusion in the study because of logistical reasons.

\section{Conclusion}

There is a need to increase the awareness of the role that paediatric endoscopy plays in the diagnosis and therapy of GI disorders in developing countries. Recurrent abdominal pain remains a relevant indication for the procedure. Every child with upper GI bleeding should certainly have upper GI endoscopy. The need to develop training programmes in developing countries on paediatric endoscopy and paediatric gastroenterology in general cannot be overemphasised.

\section{References}

1. Eisen GM, Chuntkan R, Goldstein JL, et al. Modification of endoscopic practice for pediatric patients. Gastrointest Endosc 2000;52(6):838-842

2. Jantchou P, Schirrer J, Bocquet A. Appropriateness of upper gastrointestinal endoscopy in children: A retrospective study. J Pediatr Gastroenterol Nutr 2007;44(4):440-445. http://dx.doi.org/10.1097/MPG.0b013e31802c6847

3. Bishop PR, Nowicki MJ, May WL, et al. Unsedated upper endoscopy in children. Gastrointest Endosc 2002;55(6):624-630.

4. Gilger MA, Gold BD. Pediatric endoscopy: New information from the PEDSCORI project. Curr Gastroenterol Rep 2005;7(3):234-239.

5. Franciosi JP, Fiorino K, Ruchelli E, et al. Changing indications for upper endoscopy in children during a 20-year period. J Pediatr Gastroenterol Nutr 2010;51(4):443-447. http://dx.doi.org/10.1097/MPG.0b013e3181d67bee

6. Mudawi HMY, El Tahir MA, Suleiman SH, et al. Paediatric gastrointestina endoscopy: Experience in a Sudanese university hospital. East Mediterr Health J 2009;15(4):1027-1031.

7. Khan MR, Ahmed S, Ali SR, Maheshwari PK, Jamal MS. Spectrum of upper GI endoscopy in paediatric population at a tertiary care centre in Pakistan. Open J Pediatr 2014;4(3):180-184. http://dx.doi.org/10.4236/ojped.2014.43025

8. Aro P, Ronkainen J, Talley NJ, Storskrubb T, Bolling-Sternevald E, Agréus L. Body mass index and chronic unexplained gastrointestinal symptoms: An adul endoscopic population based study. Gut 2005;54(10):1377-1383. http://dx.doi. org/10.1136/gut.2004.057497

9. Agréus L, Svardsudd K, Nyren O, Tibblin G. Reproducibility and validity of a postal questionnaire. The abdominal symptom study. Scand J Prim Health Care 1993;11(4):252-262.

10. Rawashdeh MO, Abu-Farkash N, Al-Jaberi TM. Paediatric upper gastro-intestinal endoscopy in developing countries. Ann Trop Paediatr 1996;16(4):314-316.

11. Joshi MR, Sharma SK, Baral MR. Upper GI endoscopy in children in an adult suite. Kathmandu Univ Med J 2005;3(2):111-114.

12. Hafeez A, Ali S, Hassan M. An audit of paediatric upper gastrointestinal endoscopies. J Coll Physicians Surg Pak 2000;10:13-15.

13. Okello TR. Upper gastrointestinal endoscopic findings in adolescents at Lacor Hospital, Uganda. Afr Health Sci 2006;6(1):39-42.

14. Zuleta MAG, Morales OFR, Riveros J. Diagnostic usefulness of upper gastrointestinal endoscopy for patients under 18 years of age. Rev Col Gastroenterol 2014;29(2):111-115.

15. Kawakami E, Machado RS, Fonseca JA, Patricio FRS. Clinical and histological features of duodenal ulcer in children and adolescents. J Pediatr (Rio J) 2004;80(4):321-325. http://dx.doi.org/10.2223/1207

16. Lubetzky R, Mandel D, Reif S, Bujanover Y. Special clinical manifestations of Helicobacter pylori infection in children and adolescents. Harefuah 2004;143(8):554-556.

17. Vithayasai N. Childhood Helicobacter pylori infection, clinical presentations, endoscopic, histologic features and results of treatment. J Med Assoc Thai 2003;86(3):S600-S604

18. El-Mouzan MI, Al-Mofleh IA, Abdullah AM, Al-Rasheed R. Indications and yield of upper gastrointestinal endoscopy in children. Saudi Med J 2004;25(9):1223-1225.

19. Ferreira CT, Berti MR, Pires AL, Wieczorek C, Alves J. Endoscopia digestiva alta em pediatria: Indicações e resultados [Upper gastrointestinal endoscopy in children: Indications and results]. J Pediatr (Rio J) 1998;s74(1):39-44.

20. Sheiko MA, Feinstein JA, Capocelli KE, Kramer RE. Diagnostic yield of EGD in children: A retrospective single centre study of 1000 cases. Gastrointest Endosc 2013;78(1):47-51. http://dx.doi.org/10.1016/j.gie.2013.03.168 